\title{
EDITORIAL
}

\section{Retomar a história da RBH}

\author{
Resuming the History of RBH
}

Criada em 1981, a $R B H$ tem pouco mais de 35 anos de existência. Para historiadores trata-se de um tempo relativamente curto e que poderia implicar uma dinâmica bastante pacífica de permanências de estruturas, formatos, temas, idiomas, materiais e mesmo objetivos e missões. Nada mais inexato. Um dos grandes problemas, ou quem sabe, dilemas, atuais dos periódicos acadêmicos de História é o impacto que os novos formatos de divulgação trouxeram para seus conteúdos. Nas décadas de 1980 e 1990, quando se fundou a maior parte dos periódicos nacionais da área, estes tinham como objetivo divulgar os trabalhos dos também nascentes programas de pós-graduação que os criaram, numa lógica que vinha de longe. ${ }^{1} \mathrm{O}$ objetivo da $R B H$ era substituir os Anais da Anpuh, cuja publicação havia cessado em 1979 (com as atas do simpósio de 1977), e divulgar assim, inicialmente sobretudo entre os próprios associados, os trabalhos feitos por eles (Canabrava, 1981, p. 9; Conselho de Redação da $R B H, 1984 / 1985$, p. 5). Na realidade, os anais dos encontros continuaram a existir, mas, a partir de 1979, apenas com os resumos das comunicações. Publicaram-se os textos completos das comunicações dos simpósios de 1991 e de 1993, mas a retomada definitiva deu-se apenas em 1998, com os Anais do XIX Encontro da Anpuh. É uma boa notícia que todas essas publicações estejam novamente disponíveis, completas, no site da Anpuh, depois de ultrapassados importantes problemas técnicos. ${ }^{2}$

A RBH era também, como a seção "Notícias" da revista (publicada até o seu número 30, de 1995) o demonstra, um instrumento de comunicação interna de seus associados. Hoje, a virtualização do conhecimento (se é que a expressão é justa), para além de outras razões que não vêm ao caso discutir aqui agora, levou a $R B H$ a focar fundamentalmente na produção de pesquisa de ponta, a ligação com os associados passando para outros formatos mais ágeis de comunicação. 
A passagem, dolorosa para muitos, do formato impresso para o exclusivamente digital, aconteceu na $R B H$ em 2010 , com seu número 59. Se é difícil quantificar o número de consulentes dos exemplares impressos da revista, não resta dúvida sobre o aumento exponencial no alcance de possíveis leitores que os formatos html e pdf facultam (segundo o SciELO Analytics, a $R B H$ alcançou, por exemplo, um pico de 955.169 acessos em 2017). ${ }^{3}$ Os textos já publicados e aqueles a publicar futuramente, em acesso aberto, disponíveis em diferentes bases e portais de periódicos, podem ser consultados facilmente por especialistas e por curiosos de qualquer canto do mundo, os quais chegam a eles, quem sabe, a partir de um simples googleio ou de uma menção no Tweeter. Não mais do que 15 anos atrás, a ida a uma hemeroteca bem guarnecida era essencial quando se buscava um artigo acadêmico apenas um pouco mais antigo do que isso.

Mas até que ponto o acesso a essas informações é, hoje em dia, realmente total? Foi a partir dessa pergunta que a equipe editorial da $R B H$ conferiu as informações da revista disponíveis seja no site da Anpuh seja no próprio SciELO, que alberga o conteúdo digital da $R B H$ do número 34 (de 1997) em diante. ${ }^{4}$ Percebemos assim que, no que toca aos números mantidos no site da Anpuh, mesmo se os artigos e resenhas estavam efetivamente disponíveis ao consulente da internet, não era realmente a totalidade do conteúdo dos volumes impressos que podia ser lida ali. Já agora, depois de um minucioso trabalho de conferência, todos os paratextos desses números podem ser consultados online: eventuais apresentações, editoriais e créditos de publicação. Também se fez o esforço de disponibilizar no site o sumário de época dos números antigos, muitas vezes mais diversos que o atual. Em seus primeiros números, a $R B H$ trazia, para além de artigos e resenhas, documentos, polêmicas, noticiários, notícias bibliográficas etc.

Recuperou-se também, agora nos números mais recentes, a lista dos editores e dos conselhos editorial e consultivo que, como é de praxe ao menos desde 1991, mudam a cada 2 anos, com a diretoria da Associação. Essa parte da história da $R B H$ desaparecia a cada novo mandato, já que o SciELO atualiza a cada número a lista das pessoas responsáveis por aquela edição específica, esperando sem dúvida que as revistas abrigadas na interface a mantenham de modo mais circunstanciado em sites próprios. É possível refazer essas listas editoriais por meio, por exemplo, da Wayback Machine do Internet Archive (https://archive.org/web/), mas pensamos ser obrigação da própria $R B H$ fornecer facilmente esses dados, e é por isso que desde já eles estão disponíveis na página da Anpuh. ${ }^{5}$ 
Enfim: recupera-se no site da Anpuh parte essencial do material necessário para se fazer a história da $R B H$, da evolução de seus conteúdos, de seus formatos, de suas escolhas editoriais e de suas formas de gestão. Uma história que ainda está por se fazer no que se refere de modo amplo aos periódicos acadêmicos da área no Brasil.

Este número da $R B H$, como é habitual uma vez por ano, não traz um dossiê específico, mas apenas artigos avulsos. Com artigos de autores sediados em instituições de diferentes estados, países e continentes, abordam-se temas não só relevantes como prementes quando se tem em conta o lugar do historiador no Brasil de hoje. Em conexão ampla com o tema deste Editorial, os três primeiros artigos remetem à importância de se ter um acesso o mais isento e amplo possível à informação. No dia 24 janeiro deste ano o presidente em exercício Hamilton Mourão assinou um decreto (n. 9.690) que permite a um maior número de gestores públicos classificar documentação ativa como secreta ou ultrassecreta, restringindo a amplitude da Lei de Acesso à Informação de 2011. Se a documentação utilizada por Daniel Faria e Mateus Gamba Torres para escrever "Uma história feita de retalhos: o acervo da Secretaria de Segurança Pública do Distrito Federal", pondo em claro seu valor histórico, aparentemente não corre o risco de ser retirada de consulta, a recente resolução presidencial gera preocupação na medida em que pode vir a impedir que documentação ainda não conhecida, mesmo antiga, venha a público. ${ }^{6}$ Ainda em ligação com a atualidade e a isenção da informação, Juliana Sayuri Ogassawara e Viviane Trindade Borges, em "O historiador e a mídia: diálogos e disputas na arena da história pública”, mostram as problemáticas trazidas para a historiografia pelas diferenças de linguagem e de público. As autoras discutem o papel do historiador na divulgação do conhecimento em conexão com outras áreas e as dificuldades de comunicação que surgem na transposição do "meio" acadêmico para o jornalístico ou cinematográfico. Põe-se assim em relevo o papel público que o historiador tem e deve ocupar de modo que outros não venham a fazê-lo em seu lugar. Ainda nesse veio das problemáticas da transmissão do conhecimento, Pedro Vinicius Asterito Lapera mostra como durante a Belle Époque carioca o sensacionalismo foi articulado como uma prática de comunicação dos jornais.

Seguem-se quatro artigos baseados em pesquisa inédita que abordam um arco temporal, geográfico, mas também metodológico bastante amplo: do Japão do século XVI ao Moçambique do século XIX, passando pela Angola e o Prata do século XVIII. Discutem-se temas da história religiosa a partir de 
debates teológicos; abordam-se questões da história econômica, mas também da análise de redes para a história política. Rômulo da Silva Ehalt compara as defesas jesuítas da escravidão voluntária no âmbito dos princípios do direito natural, mostrando, porém, como diferentes contextos geraram soluções díspares. Gustavo Acioli Lopes e Maximiliano M. Menz discutem o papel do contrato de fornecimento de têxteis de Angola no comércio transatlântico de escravos nas décadas de 1760 e 1770. Laura Cristina del Valle e Juan M. C. Larrosa estudam as características dos indivíduos das famílias portenhas dos anos 1776-1810 que as associavam mais ou menos ao poder político concelhio. Já Matheus Serva Pereira mostra como, durante toda a primeira metade do século XX, os agentes coloniais portugueses no sul de Moçambique escrutinizaram, mas ao mesmo tempo homogeneizaram músicas e danças que insistiram em chamar genericamente de "batuque".

Finalmente, este número traz três resenhas de livros recentemente publicados no país.

Ao lhes desejar boa leitura, não podemos deixar de agradecer ao Conselho Editorial, à Editoria Associada Internacional, aos Assistentes Editoriais Pablo Serrano e Marcus Vinicius Correia Biaggi, assim como à equipe de edição da $R B H$ - Armando Olivetti, Flavio Peralta e Roberta Accurso - pelo cuidado e atenção que sempre dispensam à revista. $\mathrm{A} R B H$ não teria a qualidade que tem sem o apoio do Programa de Pós-Graduação em História, Cultura e Práticas Sociais da Universidade do Estado da Bahia (PPGHCPS-Uneb) e do CNPq.

Bruno Feitler

Universidade Federal de São Paulo (Unifesp), Escola de Filosofia, Letras e Ciências Humanas, Departamento de História, Guarulhos, SP, Brasil. rbh@anpuh.br <http://orcid.org/0000-0003-1468-5680>

\section{REFERENCIAS}

CANABRAVA, Alice Piffer. A Associação Nacional dos Professores Universitários de História. Revista Brasileira de História, n. 1, p. 1-11, 1981.

CONSELHO DE REDAÇÃO DA RBH. Editorial. Revista Brasileira de História, n. 8/9, p. 5-6, 1984/1985.

MARTINS, Ana Luiza. Revistas em revista: imprensa e práticas culturais em tempos de República. São Paulo (1890-1922). São Paulo: Edusp, 2000. 


\section{NOTAS}

1 "De ordinário, as revistas nasciam anexas aos estatutos iniciais da agremiação, como seu instrumento legitimador, divulgando-a, dando-lhe consistência." (MARTINS, 2000, p. $330)$.

${ }^{2}$ Disponível em: https://anpuh.org.br/index.php/documentos/anais.

${ }^{3}$ A curva de acessos da $R B H$ dos últimos 5 anos é esta: 811.662 (2014), 844.332 (2015), 794.558 (2016), 955.169 (2017) e 810.226 (2018).

${ }^{4}$ Os números 1 a 33 da $R B H$ podem ser consultados em https://anpuh.org.br/index.php/ revistas-anpuh/rbh; os números 34 em diante estão em www.scielo.br/rbh.

${ }^{5}$ Disponível em: https://anpuh.org.br/index.php/revista-brasileira-historia/corpo-editorial-editorial-board/item/5033-editores-e-conselhos-atual-e-anteriores.

${ }^{6}$ Tramita atualmente no Congresso Nacional (estamos em março de 2019) um Projeto de Decreto Legislativo de Sustação de Atos Normativos do Poder Executivo (PDL 3/2019) que tem como alvo o Decreto no 9.690. Esperemos que ele avance em ambas as casas. 